\title{
The Relationship Between Body Image Concerns, Eating Disorders and Internet Use, Part II: An Integrated Theoretical Model
}

\author{
Rachel F. Rodgers ${ }^{1,2}$
}

Received: 19 June 2015/Accepted: 29 September 2015/Published online: 7 October 2015

(C) Springer International Publishing 2015

\begin{abstract}
The last decade has seen a huge rise in Internet use, including social media, particularly among youth, and preliminary evidence of a relationship between Internet use and increased body image concerns and eating pathology has emerged. However, to date, considerations of theoretical perspectives that might guide this direction of research are lacking. The aim of the present study was, therefore, to provide an analysis of the different theoretical contexts in which Internet use may be studied, and propose an integrative framework for research among adolescents. It reviews five important theoretical models of the development of body image concerns and eating pathology and discusses their usefulness as frameworks within which to explore the relationships between Internet and social media use and body image concerns and eating pathology. Specifically, it critically evaluates sociocultural theory, feminist and self-objectification theory, impression management theory, social identity theory, and gratification theory. Finally, drawing on these five theories, it presents an integrated model and proposes a framework within which to ground research focusing on the relationships between Internet and social media use, and body image concerns and eating pathology. It ends with suggestions for future research among adolescents within the proposed framework.
\end{abstract}

Rachel F. Rodgers

rodgers.rachel@gmail.com

1 Department of Applied Psychology, Northeastern University, 404 International Village, 360 Huntington Avenue, Boston, MA 02115, USA

2 Laboratoire de Stress Traumatique, Université Paul Sabatier, Toulouse, France
Keywords Internet $\cdot$ Social media $\cdot$ Body image $\cdot$ Eating pathology $\cdot$ Theory

\section{Introduction}

In recent years, Internet usage has increased exponentially, with $93 \%$ of teenagers now possessing Internet access at home (Madden et al. 2013). Youth are disproportionately high Internet and social media users, with up to $89 \%$ of $18-29$ year olds using a social network site (Brenner and Smith 2013). Furthermore, Internet access is virtually unlimited through mobile phones and other mobile devices and nearly $50 \%$ of teenagers own a smartphone in the U.S. (Madden et al. 2013). Developmentally, this is very relevant in that many of the interpersonal processes that are important for social-emotional development may now be transitioning to the online environment, which could result in poorer psychosocial wellbeing (Pea et al. 2012). Body image concerns and eating pathology also predominantly appear during adolescence, and have been shown to develop within a sociocultural context (Levine and Murnen 2009; Von Soest and Wichstrøm 2009). Together, these factors suggest a putative association between Internet use and body image and eating concerns.

Consistent with this, an increasing body of research has documented the relationship between Internet exposure and use, and body image concerns and eating pathology (e.g. Brown and Bobkowski 2011; de Vries et al. 2015; Rodgers et al. 2013; Tao and Liu 2009; Tiggemann and Miller 2010; Tiggemann and Slater 2013). However, to date, considerations of theoretical perspectives that might guide this direction of research are lacking. This is an important omission, as the Internet presents several characteristics 
that depart from traditional media and may render current frameworks insufficient, including its interactive nature, and the combination of being highly visual yet allowing immense control over self-presentation. These characteristics limit the usefulness of existing theories, as they intensify the interpersonal-and thus personal nature of the Internet and social media, and raise questions regarding the interplay between identity and self-presentation in ways which traditional theories, developed around a uni-directional model of media communication, are ill-equipped to address. Thus, the adaptation of existing theoretical models and the development of frameworks that are suited to the investigation of the effects of Internet use is a critical need.

The objective of the present study was, therefore, to provide an analysis of the different theoretical contexts in which Internet use may be viewed, and propose an integrative framework. The aim was to provide a structure within which to build future research on the relationship between Internet use and body image and eating concerns among adolescents, and to call for more work in this area.

\section{Sociocultural Theory}

Sociocultural theory has emerged as one of the primary frameworks within which body image and eating concerns has been conceptualized. This theory posits that social agents such as the media, peers, and parents convey strong messages regarding the importance of appearance, and pressure to conform to unrealistic body ideals (Brown and Bobkowski 2011; Thompson et al. 1999; Webb and Zimmer-Gembeck 2014). These messages are then internalized by individuals who adopt societal standards of beauty and slenderness as their own. The discrepancy perceived between the ideal and one's own body often results in body dissatisfaction followed by disordered eating behaviors aiming to bring one's body closer to the ideal (Thompson et al. 1999). Physical appearance comparison constitutes a second mechanism leading to the development and maintenance of body image and eating pathology, as in many instances comparisons are not favorable, especially when media images are chosen as comparison targets (Levine and Murnen 2009). The sociocultural theory of body image and eating concerns' focus on media, peers, and parents as socializing agents has made it developmentally very relevant to adolescents and youth (Borzekowski and Bayer 2005; Clay et al. 2005; Rodgers et al. 2009; Webb and Zimmer-Gembeck 2014).

The media, in particular, have been shown to present a relentless stream of images of ideal bodies, almost without exception carefully digitally modified to create an unattainable image of physical perfection (Hunter 2011). Furthermore the weight-loss industry, representing over
$\$ 50$ billion in North America, promotes products promising an immediate solution to perceived imperfections and physical transformations through little or no effort (Freedhoff and Sharma 2009). A wealth of correlational, prospective and experimental studies has provided support for the role of media exposure in the development of body image dissatisfaction and eating pathology among adolescents and suggested that media exposure might be a causal risk factor for these concerns (Levine and Murnen 2009).

Peers represent another important source of sociocultural influence during adolescence and young adulthood. Adolescents who conform to social ideals of appearance are typically more popular and provide an example of the rewards of conformity and the pursuit of social ideals (Wertheim et al. 1997). Peer feedback has also been shown to have an impact on body dissatisfaction (Salafia and Gondoli 2011). Teasing particularly has revealed an association with body dissatisfaction (Lampard et al. 2014; Neumark-Sztainer et al. 2002; Paxton et al. 1999). Furthermore, fat talk-that is conversations focusing on weight and appearance and involving explicit self-deprecating statements, complaints regarding personal physical appearance, and weight management tips-is related to body image and eating concerns (Nichter and Nichter 2001; Sharpe et al. 2013). From a network perspective, friendship cliques have also been shown to report similar body image and eating concerns, a phenomenon sometimes referred to as peer contagion (Hutchinson and Rapee 2007; Paxton et al. 1999). Furthermore, appearance-related comments from friends have been found to reinforce the relationship between body dissatisfaction and disordered eating (Forney et al. 2012). Thus, peers have been shown to constitute an important source of influence on body image and eating concerns among adolescents.

Within sociocultural theory, particular attention is paid to physical appearance comparison as one of the mechanisms proposed to account for the relationship between sociocultural pressures to achieve appearance ideals and body image concerns and eating pathology (Schutz et al. 2002; Rodgers et al. 2014; van den Berg et al. 2002). Consistent with this, media-ideal internalization and appearance comparison have emerged as mediators of the relationship between sociocultural influences and body dissatisfaction and eating pathology among adolescent girls (Keery et al. 2004). Thus, appearance comparison plays a critical role in the impact of sociocultural influences on body image and eating concerns.

\section{The Role of the Internet}

Having described the sociocultural theory of body image concerns and eating pathology, the aim is to examine how the Internet may fit into sociocultural models (Fig. 1). The 


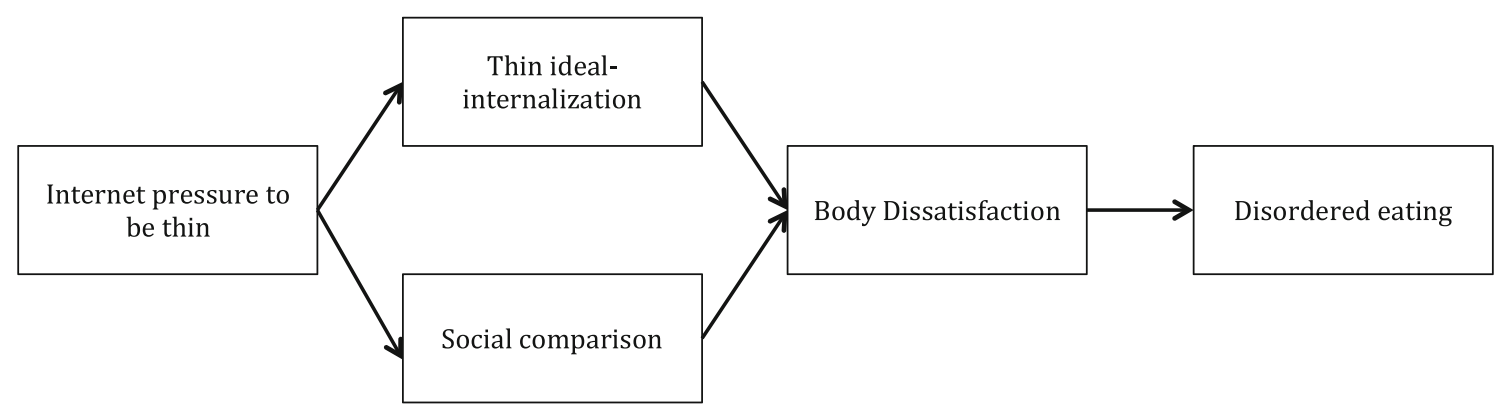

Fig. 1 Internet influences within sociocultural models of body image concerns and eating pathology

Internet, particularly through the use of social media, can be considered to combine aspects of both media and peer influences, as the Internet provides a vehicle for images portraying appearance ideals as well as an interactive medium allowing for peer feedback, through applications such as Facebook, Twitter and Instagram. As a form of media pressure, one of the Internet's strongest means of influence is advertising. A content analysis of advertisements on popular websites targeting teenagers revealed that advertisements for cosmetic and beauty products were the most represented (Slater et al. 2012). Interestingly, the majority of the websites reviewed targeted girls only. Furthermore, personalized advertising occurs with increasing frequency on the Internet, involving the delivery of advertisements based on the previous data collected on a particular user in order to best target their interests (Yu and Cude 2009). This is common-practice and nearly all websites collect great amounts of personal information from consumers (such as search terms) to create personal profiles (U.S. Federal Trade Commission 2000). As one of the main uses of the Internet reported by adolescents is for obtaining information regarding diet, fitness and exercise (Borzekowski and Rickert 2001), searching for this type of information, therefore, results in adolescents' being targeted with weight-loss and fitness advertisements, potentially exposing them to a narrower and more greatly appearance-focused range of advertising than would occur, for example, on television. Thus, the Internet appears to constitute an additional source of appearance-focused media.

In terms of peer influence, the Internet and social media allow the occurrence of appearance-centered interactions, negative appearance-related feedback and the modeling of these behaviors by exposing individuals to examples of weight-based teasing or stigmatization. For example, a content analysis of videos displaying fat-stigmatization on YouTube unearthed a sample of 493,000 results, with certain videos viewed almost 2.5 million times suggesting that this type of media content has an extremely high potential reach (Hussin et al. 2011). Similarly, Twitter contains high levels of appearance-focused content (Fernandes et al. 2013). Regarding direct peer influences, cyberbullying related to appearance occurs frequently on the Internet among adolescents (Frisén et al. 2014), and constitutes an emotionally very impact form of peer influence. Peers may also amplify the appearance-focus on the Internet by intensifying the presence of certain pictures, or messages (through generally circulating the content by "liking" "retweeting" etc.) as well as mediating the effect of Internet content by adding meaning and valence to it. Similar processes of the mediation of media content by parents have been described in the context of media effects of body image and eating concerns (Nathanson and Botta 2003). Thus, in many ways, the Internet may also represent a source of peer influence, or perhaps, an intersection between media and peer influences.

The Internet and social media also offer multiple opportunities for social comparison. The images presented on the Internet are often those of other users and, therefore, likely to be considered appropriate targets for appearance comparison. Interactive applications such as allow users to post pictures and follow the pictures posted by others. A large amount of the content on these websites appears to be devoted to appearance ideals. Instagram and Tumblr, two social networking sites, also host events such as "transformation Tuesday" encouraging users to post "before and after" pictures, frequently focused on weight-loss. Thus, the Internet and social media may promote social comparison, leading to body dissatisfaction and eating pathology.

\section{Usefulness of Sociocultural Theory}

The Internet appears to provide an exceptional arena for sociocultural influences, both through exposure to media images and messages as well as peer influences in terms of weight- and shape-focused interaction and feedback. The potential for the online environment to become highly saturated in appearance-related content based on individuals' interests makes sociocultural models very relevant. 
Similarly, the disinhibiting effect of anonymity in online peer networks may encourage appearance-related teasing and negative feedback (Suler 2004). Thus, the sociocultural framework, which considers these influences, might be particularly appropriate. The sociocultural framework also presents a number of limitations, however. Firstly, while it may theoretically consider bidirectional relationships between individuals and their sociocultural environment, the model does not operationalize these in any way. This is a critical shortcoming as the online environment is constantly changing and shaped by user actions through targeted advertising, group membership, and user contributions. Secondly, the sociocultural theory fails to conceptualize potential differences between exposure to industry created images of appearance ideals, and exposure to digitally modified images from one's social circle, and their differential effects on body dissatisfaction and eating pathology. Finally, sociocultural theory fails to incorporate the effects of participating in creating Internet appearancefocused content. Thus, while clearly presenting a number of strengths, sociocultural theory is also limited in its usefulness as a framework for the investigation of the relationship between Internet use and body image and eating concerns.

\section{Self-Objectification and Feminist Theory}

In feminist theories of the development of body image and eating concerns, the Western focus on female appearance that encompasses both the glorification of thinness and the vilification of fatness, is viewed as a form of sexism and misogyny, and therefore as a means of maintaining the patriarchal status quo (Brown 1989). The relentless promotion of thinness serves the interests of the diet and beauty industry as well as hampering women's empowerment and sense of self-efficacy by maintaining an anxious focus on appearance (Gilbert and Thompson 1996). Furthermore, feminist theories of body image and eating concerns highlight the conflicting attitudes surrounding the increasing social success of women, and suggest that women are motivated to try to conform to societal standards of appearance in order to assuage male anxieties resulting from their growing role in society, and gain male approval (Gilbert and Thompson 1996). Consistent with these theories, meta-analytic findings have shown a positive association between feminist identity and positive body image and lower eating pathology among women (Murnen and Smolak 2009), suggesting that heightened feminist consciousness may help adolescent girls to engage in critical appraisal of their cultural environment and resist sociocultural pressures. Furthermore, feminist identity has been found to moderate the relationship between the perception of sexist events and disordered eating (Sabik and Tylka 2006). Thus, feminist theories of the development of body image and eating concerns have received empirical support.

Another important concept developed by feminist theories of body image and eating concerns is the objectifying male gaze. Objectification can be defined as the tendency to treat bodies as objects as opposed to entities (Fredrickson and Roberts 1997). In other words, through objectification, individuals, particularly women but increasingly men as well, are considered and treated "as bodies". Selfobjectification refers to the tendency to join society in viewing oneself as an object. Thus, self-objectification theory posits that Western society socializes its members to treat themselves as objects to be evaluated, and in many cases, sexual objects (Fredrickson and Roberts 1997). From a theoretical standpoint, self-objectification would contribute to body dissatisfaction and eating pathology through the resulting experiences of increased body-related anxiety, shame and surveillance (McKinley and Hyde 1996). A robust body of work has supported objectification theory and the usefulness of considering body image and eating pathology within this framework, and provided evidence for the relationship between self-objectification and body dissatisfaction and disordered eating in women (e.g. Slater and Tiggemann 2002), as well as muscularity concerns in early adult males (Daniel and Bridges 2010). Furthermore, media content analysis has revealed the ubiquitous presence of objectifying images of women and men (Rohlinger 2002; Stankiewicz and Rosselli 2008). Media and peer influences have also been linked with increased levels of self-objectification among adolescents, suggesting that being exposed to images of ideal figures heightens feelings of objectification (Aubrey and Frisby 2011; Knauss et al. 2008; Lindberg et al. 2007). In this way, self objectification theory has emerged as a useful lens through which to conceptualize body image and eating concerns.

\section{The Role of the Internet}

As feminist theory hypothesizes that patriarchal messages are conveyed by mainstream society, Internet and social media use could potentially be explored within this framework (Fig. 2). Early cyberfeminists saw the disembodied space of the Internet as possessing a high potential for combatting gender inequalities (Fahs and Gohr 2012). Consistent with this, the Internet has been described as a libratory space in which minority voices can be expressed and heard, patriarchal discourse challenged, and where youth can experience greater freedom of expression (Bosch 2011; Walsh 2008). However, other authors have highlighted the tendency for the homogenizing patriarchal discourse to dominate cyberspace, going so far as to term it 


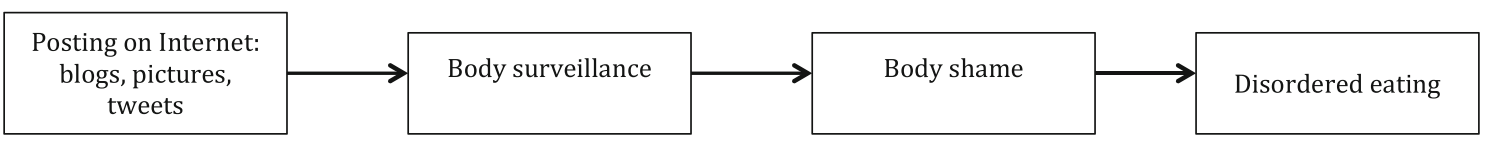

Fig. 2 Internet influences within self-objectification models of body image concerns and eating pathology

a "superpatriarchy" (Fahs and Gohr 2012). In this way, while promising emancipation into an androgynous space, the Internet replicates and amplifies traditional gender scripts (Fahs and Gohr 2012). Social media, in particular, can be seen as providing an illusion of personal expression and unconstrained identity while subtlety allowing only a narrow and controlled range of ways in which to express identity. As noted by other authors, Facebook, for example, offers users the opportunity to "like" content but has no corresponding "dislike" function (Fahs and Gohr 2012). These observations suggest that Internet and social media use may maintain individuals in a space in which patriarchal discourse and capitalism are the dominant voices, and that feminist theory might, therefore, be a useful framework for conceptualizing the effect of the Internet.

In addition to the previously mentioned content, the Internet provides access to sexually explicit content with more ease than ever before. It has been suggested that a large proportion of youth come into contact with sexually explicit Internet content, which has been associated with the perception of women as sex-objects (Doornwaard et al. 2015; Peter and Valkenburg 2007). Regarding more interactive forms of exposure to sexual content, up to $32 \%$ of young adults and $19 \%$ of adolescents have reported sending nude or semi-nude photos of themselves (The National Campaign to Prevent Teen and Unplanned Pregnancy 2008). Furthermore, themes of objectification and body display were found in over $25 \%$ of the female profile photos posted on MySpace (Hall et al. 2012). These findings suggest that the Internet may promote both the sexual objectification of others and self-objectification.

While it could be considered that the anonymity of computer-mediated communication might allow individuals to remove themselves from society's objectifying gaze, the opposite has also been argued: "one enters the online world very aware that he/she is being observed, monitored, judged... The assumed male gaze is ubiquitous" (Donnelly 2011, p. 174. This assumed male gaze is well-illustrated by "attractiveness" being the most frequently cited motivation reported by Facebook users regarding their choice of profile photo (Strano 2008). Facebook also offers the option of being "tagged" in a photo- that is creating a link between an individual in a photo and their personal profile. While women report engaging in this more than men, they have also been suggested to "untag" photos of themselves more frequently, the most common reason being dissatisfaction with their appearance (Pempek et al. 2009). Other forms of objectifying content can be found through websites and applications that allow users to rate the physical attractiveness of other users. It is easy to imagine the increasing feelings of self-objectification arising from the awareness that every member of your peer group is equipped with a camera-phone and that every moment is susceptible to be captured and circulated on the Internet, with or without your consent. Consistent with this, Internet use has been found to be associated with high levels of self-objectification among adolescent girls (e.g. Tiggemann and Slater 2013). Thus, this framework seems to present some usefulness for the examination of the relationship between Internet and social media use, and body image concerns and eating pathology among adolescents.

\section{Usefulness of Feminist and Self-Objectification Theory}

The Internet and social media promote the availability of sexual content as well as extending the space submitted to the objectifying male gaze to cyberspace by creating opportunities for online identities to be judged and evaluated by others. Internet exposure and new social media sites provide conditions that might promote self-objectification both through the invitation to constantly update one's profiles, resulting in the perception of being in the gaze of others, and through the presence of readily available explicitly objectifying content. Thus, feminist and self-objectification theory seem to contribute a valuable lens through which to explore the relationships between the Internet and body image and eating pathology.

Similarly to sociocultural theory, however, the usefulness of this framework is limited by its lack of consideration of the contributions of users to the Internet and social media, as well as online gratifications. Thus, the degree to which individuals contribute images of themselves to online profiles, sometimes with the specific intention of them being appraised (and objectified), may result in different psychological effects compared to the sensation of being objectified in a manner that is out of one's control. Furthermore, traditionally, when considering the impact of media, objectification theory has considered that individuals, and particularly girls, are socialized within an environment rich in objectifying but impersonal images, rather than experiencing their own image being circulated and 
objectified as may occur on the Internet. The usefulness of feminist and self-objectification theory is therefore also tempered by a number of limitations.

\section{Impression Management: Self-Discrepancy and True Self Theories}

Theories of self-presentation and impression management posit that in social situations individuals attempt to control their image and identity-relevant information (Cialdini and de Nicholas 1989; Schlenker 1980). Thus, motivated by the desire to gain social acceptance or approval, individuals will try to portray themselves in the way that they consider to be the most attractive or desirable and selectively present information about themselves in order to convey this image. In addition, however, individuals are also motivated to present themselves in a way that is congruent with their perception of their true selves, and obtain acceptance. Selfpresentation is therefore guided by the tension between creating a desirable impression and painting an authentic picture.

Higgins' (1987) self-discrepancy theory posits that the discrepancy between multiple selves is related to emotional and behavioral consequences. Specifically, it distinguishes between an ideal, an ought, and an actual self. The perceived failure of the actual self to live up to the ideal and ought selves, is hypothesized to result in negative affect and anxiety and to lead to behaviors aiming to decrease the discrepancy (Higgins 1987). Within the field of eating disorders, perceived discrepancies, both in terms of physical appearance and personal characteristics and achievements, have been hypothesized to result in body image concerns and eating pathology (Forston and Stanton 1992; Szymanski and Cash 1995). Consistent with this, self-discrepancies have been shown to be associated with eating disorder symptoms among college women (Snyder 1998). In addition, among individuals suffering from eating disorders, greater actual/ideal and actual/ought discrepancies have been found to be associated with greater severity of psychopathology (Lavender et al. 2013). Furthermore, discrepancies between actual and ideal body images have been shown to be associated with disordered eating and body dissatisfaction among young women (Anton et al. 2000; Szymanski and Cash 1995). These findings therefore provide support for self-discrepancy theory.

Other theories have highlighted the presence of a true self consisting of existing characteristics that are not fully expressed in one's present social life (Rogers 1951). Here the distinction lies between a self fully known only to the individual, and the public self. Perceived pressures to silence the true self are theorized to result in emotional and behavioral difficulties, and judging oneself by external standards (Rogers 1951; Zaitsoff et al. 2002), while expression of one's true self is associated with psychological well-being (Schlegel and Hicks 2011). In the context of eating disorders, the inability to express and the suppression of the true self have been suggested to lead to over-reliance on external standards of appearance and others' expectations, which result in high levels of body image concerns and eating pathology (StriegelMoore et al. 1993; Zaitsoff et al. 2002). Consistent with this, experiencing the public self as a fraudulent representation of one's real self has been associated with eating disorder symptoms among adolescent girls (Norwood et al. 2011). Similarly, self-silencing and the perception of not being really known by others has been associated with body dissatisfaction and eating pathology in female adolescents (Buchholz et al. 2007). These findings support the usefulness of the true self theories as an explanatory framework for the development of body image and eating concerns.

\section{The Role of the Internet}

While the Internet is by definition a disembodied space, it has been argued that adolescents are particularly likely to use the Internet for self-presentation purposes and that through most online activities users create some form of presented body image and embodied self, and that (Mazur and Kozarian 2010; Young and Whitty 2011). This embodied self is often closer to the desired or ideal self that might be achieved offline (Young and Whitty 2011). In this way, for example, profiles on online dating sites frequently include minor deceptions regarding users' physical attractiveness (Toma and Hancock 2010), and an analysis of these websites revealed that $86 \%$ of participants thought that other users were likely to misrepresent their physical appearance (Gibbs et al. 2006). However, even in other contexts of online presentations, users have a tendency to present an ideal self. Profile photos on social media sites are frequently digitally manipulated to enhance the appearance of users (Reich 2010). Furthermore, successfully enhancing one's appearance on social media is considered by adolescents to be one of the most important skills for achieving popularity online (Siibak 2009). Overly enhancing one's appearance is associated with social consequences, however, and may be perceived as deceptive (Sessions 2009), highlighting the importance of portraying a self that is perceived as not unreasonably discrepant from the real self. Therefore self-presentation on the Internet is an important but delicate task.

In the context of body image and eating disorders, the construction of an online self that is felt to be closer to one's ideal self, as compared to one's offline actual self, 
may lead to increased dissatisfaction with the actual physical self. Thus, constructing an online embodied self that one may never be able to achieve could result in higher body image concerns and, potentially, eating disorder behaviors aiming to bridge the gap between one's offline and online presentations. Furthermore, other authors have suggested that rather than an ideal self, which suggests something perfect and therefore unlikely to be obtained, online presentations might present a promised self, or the true self yet to emerge (Ellison et al. 2012). Thus, the enhanced online self is perceived more as a future self to be achieved shortly through self-improvement. Given how the present social discourse offers extreme weight control strategies as a principal means of self-improvement (Hesse-Biber et al. 2006), efforts to achieve this promised self might easily lead to eating pathology. In this way, presenting an enhanced version of oneself in the online world might be associated with body image and eating concerns in the offline world.

In addition, the Internet is a space in which aspects of the self that are not readily communicated through face-toface communication may be more easily portrayed, allowing individuals to express their true selves, particularly aspects which may be perceived as less socially desirable (Bargh et al. 2002). Furthermore, online relationships built upon disclosure of the true self are more likely to successfully transition to offline (McKenna et al. 2002), suggesting that they possess an increased degree of authenticity and reciprocity. Within the context of eating disorders, the Internet might allow for greater expression of the true self, emotions and personal characteristics that are perceived as needing to be silenced in the offline world. Being able to express these aspects of the true self in the anonymity of the online environment, and potentially transition relationships based on the true self, offline, might constitute a protective factor for eating disorders. In addition, it has been suggested that adolescents frequently use the Internet to aid them in their quest for clarity of selfconcept, therefore these theories might be particularly relevant to this developmental period (Valkenburg and Peter 2011). The relationship between Internet use and body image and eating concerns from this viewpoint is illustrated in Fig. 3.

\section{Usefulness of Impression Management Theory}

Through its highly visual nature as well as the opportunity for very high levels of control of self-presentation, the Internet is an important outlet for impression management. Correspondingly, impression management theory offers an interesting framework within which to conceptualize the effects of the Internet and social media use, which takes into account many of the distinctive features of Internet use (Fig. 3). Thus, impression management theory helps to conceptualize the creation of online selves and how their perceived distance from actual offline selves might result in body image concerns and eating pathology.

Impression management theory also presents some limitations in the framing of the relationships between Internet and social media use, and body image concerns and eating pathology in that it fails to account for the sociocultural pressures shaping the ideal or promised self that individuals try to present. Furthermore, it lacks a description of the psychological processes and individual differences accounting for the existence of discrepancies between online and offline presentations. Finally, it would be useful to provide an understanding of how online and offline presentations may reciprocally influence each other. It may be, for example, that, as an individual successfully modifies their offline appearance to more closely resemble the online self, the online self shifts a little closer to the ideal, thus remaining out of reach. In sum, despite its advantages, impression management theory is also limited in its usefulness as a framework within which to explore the relationship between Internet use and body image and eating concerns.

\section{Social Identity Theory}

Social identity theory proposes that one's sense of personal identity is drawn from knowledge of social group membership (Tajfel 1982). As a result, individuals are likely to

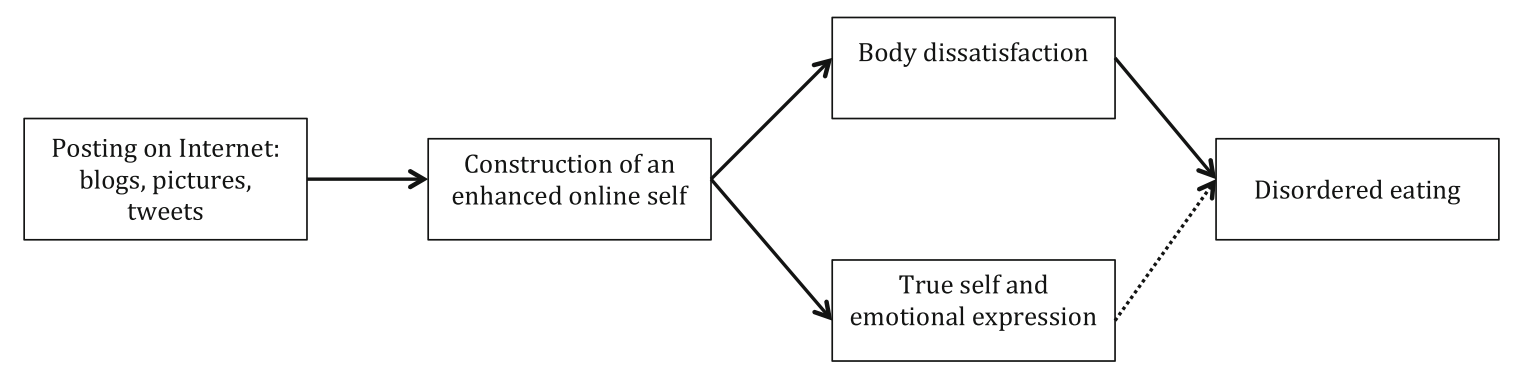

Fig. 3 Internet influences within impression management models of body image concerns and eating pathology 
engage in social categorization (perceiving the social environment in terms of in-group and out-group), rely of stereotypic characteristics of groups, and use social comparison processes as a means of preserving a positive identity (Tajfel 1982). Body image concerns and eating pathology have both been described within a social identity framework (Ison and Kent 2010). As previously described, physical appearance plays a central role in identity. Consistent with social identity theory, in order to maintain a positive identity individuals need to experience feelings of membership to a desirable group in terms of appearance and to sustain this with positive social comparisons. In Western society, in which there is an emphasis on a generally unachievable body shape, it is likely that individuals may experience difficulties trying to maintain their identity as part of this ingroup, and finding targets for positive social comparisons. The ingroup can be defined in various ways such as, for example, the peer group. Thus, adolescent girls have been reported to associate body satisfaction with the recognition that certain members of their peer group are more attractive than them while others are less so (Krayer et al. 2008). Gender group and gender role identity has also been hypothesized to be associated with body dissatisfaction and disordered eating in that investment in appearance is considered to be a feminine trait, therefore, women for whom gender is a salient identity trait will be more likely to invest in their appearance (Cash et al. 2004). Consistent with this, stress resulting from adherence to rigid traditional feminine roles has been associated with disordered eating (Mussap 2007). Thus, social identity theory has received support as a framework for examining body image and eating concerns.

Severe eating disorders such as in Anorexia Nervosa and Bulimia Nervosa have also been described as central elements of an individual's identity. In this way, the disorder becomes one of the primary characteristics around with the self is constructed and relationships with others are formed (Rich 2006). Here, the disorder is viewed as a salient characteristic for social categorization, to be shared with other members of the ingroup. One of the particularities of these disorders is the wish to retain the symptoms, and the refusal to view them as problematic but rather as egosyntonic (Vitousek and Hollon 1990). Social identity theory may, therefore, be particularly useful when considering the clinically severe forms of eating disorders.

\section{The Role of the Internet}

The Internet allows access to a much wider variety of social groups than are included in an individuals' offline network and is therefore interesting to consider within a social identity theory framework. The Internet has allowed individuals to be virtually connected and to form online groups that do not require physical proximity. Thus, marginal interests or behaviors, which may have once represented a peripheral part of an individual's identity, are now able to take a more central role through the creation of online groups of like-minded people. Similarly, individuals who experience ostracism or stigma are able to form supportive communities. One example of this is pro-eating disorders groups. While individuals with eating disorders who view their concerns as part of their identity might seek to connect with others with similar concerns offline (Rich 2006), the prevalence of these disorders is relatively low (Hudson et al. 2007), and these diseases are associated with high levels of social ostracism and stigma (Stewart et al. 2008), rendering the creation of physical pro-eating disorder groups very difficult. On the Internet, however, the creation of groups supporting eating disorders as an identity choice is much more readily achieved, and a number of authors have reported on "Pro-eating disorder" websites (Sharpe et al. 2011).

Pro-eating disorder websites advocate for disorder eating behaviors and extremely low body-weight as a lifechoice (Rodgers et al. 2012). The typical content of such web pages includes pictures of very thin celebrities, "thinspirations" (sometimes digitally modified so as to appear even thinner) (Borzekowski et al. 2010). They also include advice or tips on how to maintain disordered eating symptomatology, including extremely unhealthy weightloss methods or techniques for concealing symptoms (Borzekowski et al. 2010). Most importantly, however, they often include some means of interactive communication, via noticeboard, blog, or instant messaging. Through this interactive component, members provide each other with encouragement and support, and co-construct their eating disordered identity. Content analyses of these interactions have highlighted the importance of shared deception-through hiding ingroup practices from the outgroup. Thus, while eating pathology is a central aspect of identity for the users, it must remain hidden from friends and family for fear of stigma or imposed treatment (Borzekowski et al. 2010; Sharpe et al. 2011). Importantly, exposure to these websites has been suggested to contribute to the development or exacerbation of eating disorder symptomatology among female adolescents (Custers and van den Bulck 2009).

Despite the incentives to maintain or intensify symptomatology found on pro-eating disorder websites, many studies have found the provision of social support to be one of the main motivations for online community members and bloggers (Rodgers et al. 2012). A number of online support groups for eating disorders that are pro-recovery also exist, and have been shown to provide both information and emotional support (Eichhorn 2008). Furthermore, 
online groups may fulfill needs that face-to-face groups have more difficulty meeting, such as being available late at night (Winzelberg 1997). In this way, pro-eating disorder online communities may also have benefits for their members.

Pro-eating disorder online communities are an extreme example of appearance-centered online groups. As public policies become stricter, these websites are banned by an increasing number social media such as Pinterest and Tumblr. These groups are not the only type of body shape and eating related groups found online, however. More positive forms of these groups include activists forums, such as the Body Positive movement, the Beautiful Body Project, or the Every Day Sexism Project, and other groups aiming to promote positive body image and healthy eating practices. These websites and groups use the Internet as a medium of drawing together individuals who do not endorse the promotion of the social beauty ideal. In sum, while pro-eating disorder online groups may be the most salient due to their extreme beliefs and behaviors, other types of online communities may be associated with decreased body image and eating concerns (Fig. 4).

\section{Usefulness of Social Identity Theory}

The Internet and social media offer many opportunities for online group membership, and social identity theory provides a useful framework within which to explore the creation of groups capitalizing on the egosyntonic nature of eating disorder symptoms, as well as focusing more general on appearance, weight, and shape, and therefore seems a useful perspective for the study of the effects of the Internet and social media (Fig. 4). One of the valuable contributions of social identity theory is the consideration of online interactions, not just in terms of feedback regarding online presentation, but also in terms of relationships and social support. Adolescents have been suggested to be most likely to use the Internet for self-disclosing to their peers around the age of 15 (Valkenburg and Peter 2007), suggesting that these aspects are very relevant to this age group. This theory highlights the relational aspect of the Internet and the importance of the bonds formed online. However, social identity theory also presents a number of limitations including the lack of conceptualization of the differences between online and offline identities and relationships, and the consequences of the clash between norms and social consensus obtained in online groups, and those in the offline world. Furthermore, this theory places little emphasis on the visual nature of the Internet and how images of the self and others dominate the online world. Finally, it neglects that much of Internet and social media content is corporate-produced rather than individually produced, and how this might influence online identity construction. Therefore, similarly to the other frameworks reviewed above, social identity theory presents both strengths and limitations as a framework within which to conceptualize the relationship between Internet use and body image and eating concerns.

\section{Gratifications Theory}

Gratifications theory has also been used to conceptualize body image concerns and eating pathology (FitzsimmonsCraft 2011). Contrary to sociocultural theory, gratifications theory restores the agency of the individual in seeking out media exposure and selectively tailoring their media environment to their choices (Hesse-Biber et al. 2006). According to this theory, individuals are motivated to selectively expose themselves to cultural messages as a source of information on appearance standards (Tiggemann 2003). Such active and deliberate exposure to social messages regarding thinness may then produce different outcomes compared to passive exposure (Fitzsimmons-Craft 2011). Consistent with this theory, it has been shown that exposure to fashion magazines and television thin-ideal content has differential associations with body image and eating variables, suggesting that individuals may seek out these media for different reasons and report different impacts among college women (Lin and Reid 2009; Tiggemann 2003). Furthermore, individual characteristics and motivations to select media are thought to interact with exposure, thereby producing differential effects in different individuals (Hesse-Biber et al. 2006). Consistent with this, the magnitude of the deleterious effects of media exposure on body satisfaction among college women has been shown to be associated with initial levels of trait body dissatisfaction (Posavac et al. 1998; Rodgers and Chabrol 2009). Thus, individuals with higher initial concerns seem more greatly affected by exposure to ideal images. Gratifications theory, therefore, offers a more active account of media influences on body image and eating concerns.

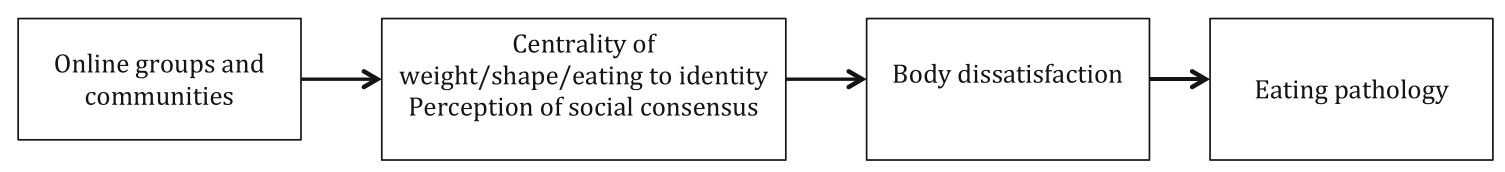

Fig. 4 Internet influences within social identity models of body image concerns and eating pathology 


\section{The Role of the Internet}

It has been argued that gratifications theory is uniquely suited to exploring online communication and behaviors, particularly among adolescents, and it has been used to explain traditional Internet use and well as social media use (LaRose and Eastin 2004; Peter et al. 2005; Raacke and Bonds-Raacke 2008). Contrary to traditional theories of media use, gratifications theory adopts a user-level perspective and considers how users are motivated to use the Internet and social media for personal satisfaction. Thus, the Internet is satisfying both in the user-directedness and control of the process, the scope of the available content, and the social aspect (Stafford et al. 2004). In the context of body image concerns and eating pathology, this may translate to the Internet being appealing through control of self-presentation, the availability of appearance, diet, and weight and shape-related content, and the capacity for social interaction. Furthermore, within gratifications theory, user characteristics modify the relationship between media use and outcomes. Thus, characteristics such as trait body image, self-esteem, need for belonging and media literacy might moderate the relationship between Internet and social media use and body dissatisfaction. Gratifications theory therefore brings together many of the aspects highlighted separately in sociocultural theory, impression management theory, and social identity theory. It offers a more integrative view of the ways in which Internet and social media use are related to body image and eating disorders (Fig. 5).

\section{Usefulness of Gratification Theory}

Gratifications theory possesses a number of important assets as a framework within which to conceptualize and explore the relationships between Internet and social media use and body image and eating pathology. Firstly, the emphasis on the active and gratifying nature of Internet and social media use seems to capture well the nature of social networking behavior. In addition, the emphasis on the selection of different contents based on motivations, as well as the modulation of the effects of exposure to these contents depending on user characteristics is particularly useful. Gratifications theory thus contributes to clarifying why individuals engage in various online activities, and how this might moderate the impact of the Internet and social media on body image and eating pathology.

Gratifications theory, however, also presents a number of limitations in that it focuses very much on individual differences to the exclusion of differences in the types of content and activities as explanatory factors for the variable effects of Internet use. Furthermore, it fails to capture online interactions with others and the important part they play in the relationship between Internet and social media use and body image concerns and eating pathology. Taken alone, therefore, gratifications theory is insufficient as an explanatory framework for examining the relationship between Internet use and body image and eating concerns.

\section{An Integrated Theory}

\section{Presentation of the Model}

Five different theoretical frameworks have previously been described to consider the relationship between Internet and social media use and body image and eating pathology. All five theories present different aspects of particular usefulness as a framework to consider these relationships, however, taken separately, they also present limitations. This article proposes an integrative framework based upon these (Fig. 6).

The integrated theory proposes that individuals may use the Internet and social media in three main ways with increasing levels of interaction. First, the Internet may be used as an impersonal tool, without interaction with others through it. Importantly, this is not a unidirectional use, since, as previously described, a user's online environment

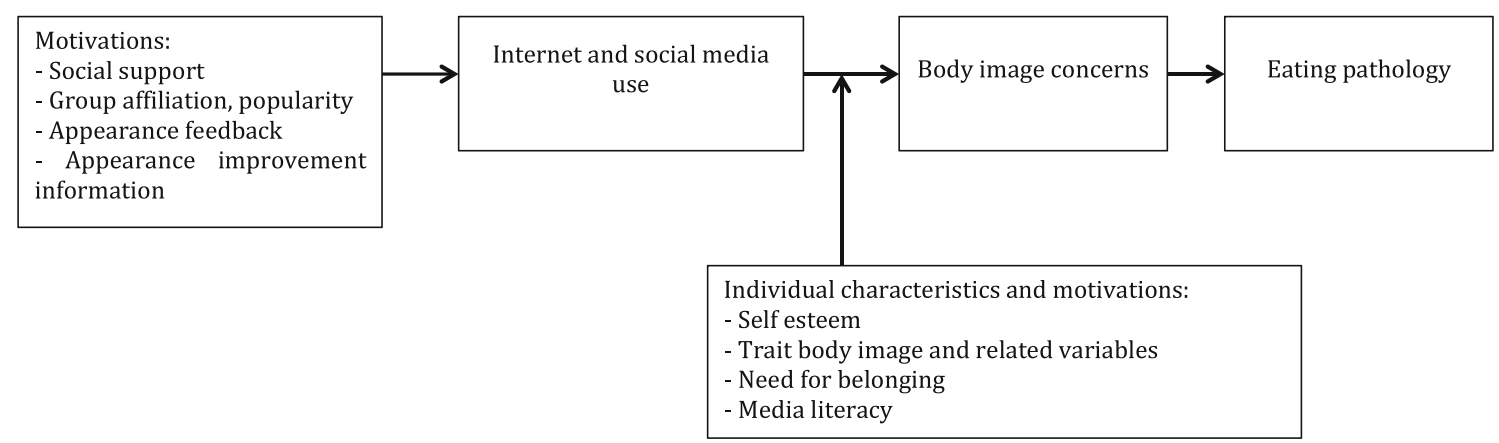

Fig. 5 Internet influences within gratifications models of body image concerns and eating pathology 
is modeled by previous uses through saved searches and personalized marketing. However, this mode of use does not incorporate any peer feedback, which constitutes and important distinction from the next two, and can therefore be referred to as "non-participatory" (as a note, as social media becomes increasingly popular, and given that social interaction is one of the main gratifications of Internet use, it is likely that fewer and fewer users engage exclusively in this type of Internet use). This type of engagement with the Internet resembles traditional sociocultural theory, and would result in increased thin-ideal internalization, leading to body dissatisfaction and eating disorder symptoms, through the mediated pathway of social comparison (Rodgers et al. 2015).

Second, the Internet may be used as a general social platform through friend-network websites such as Facebook or MySpace, and social media applications such as Twitter and Instagram. Through this mode of use, individuals contribute content to the Internet, and create one or several online presentations. Others may comment on these contributions (posts, photos, etc.) resulting in the shaping and modeling of one's online presentation in response to this

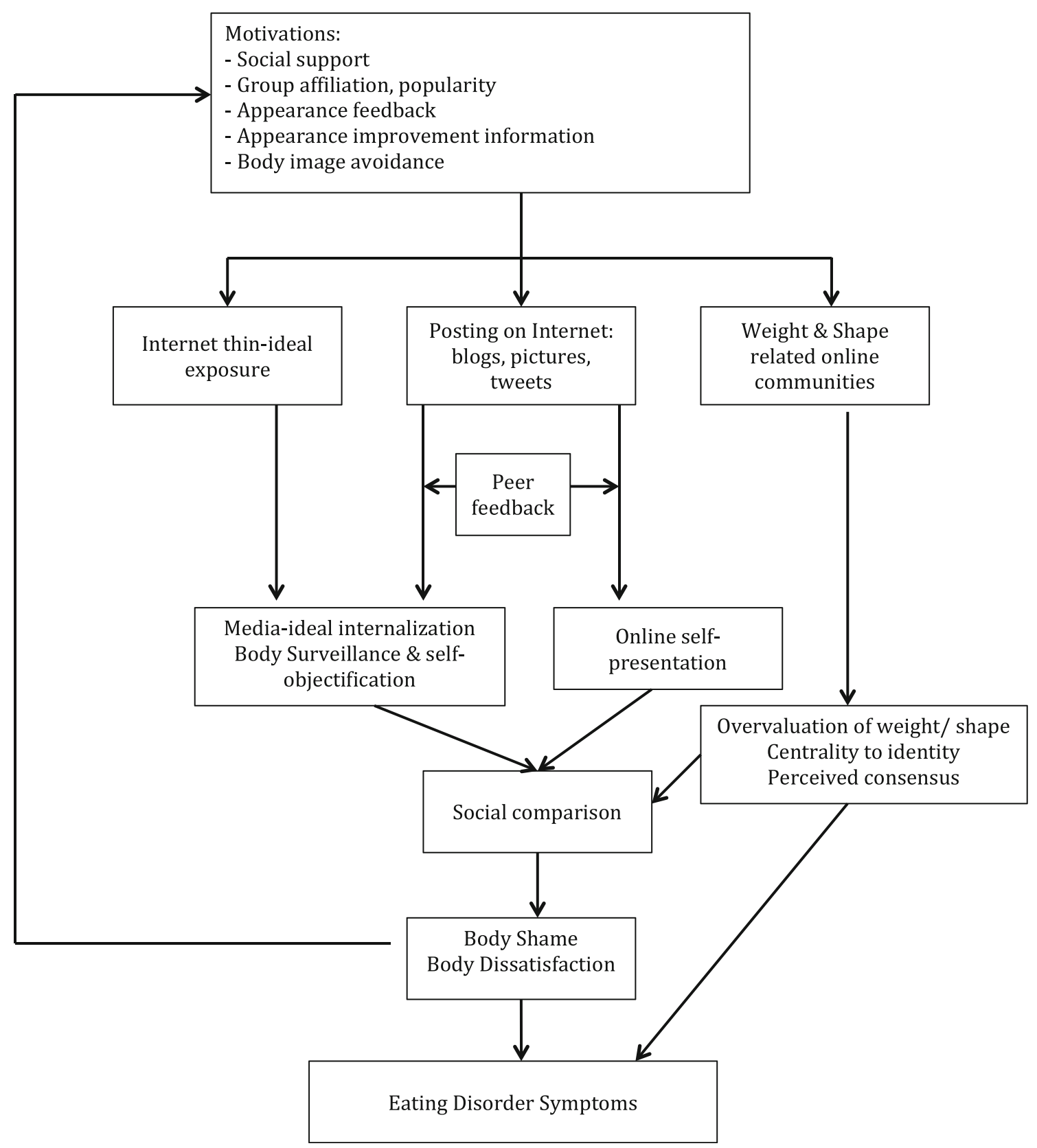

Fig. 6 An integrated model of the influence of Internet on body image concerns and eating pathology 
feedback. Furthermore, peer feedback is likely to heighten thin-ideal internalization and body-surveillance as one's life (and appearance) is increasingly viewed from the perspective of other Internet users. Both of these factors might then lead to body shame, body dissatisfaction and eating disorder symptoms, as described in self-objectification theory. Of note, both positive and negative peer feedback would likely reinforce this pathway. In addition, the increased reliance on external standards of self-evaluation might lead to more frequent online contributions in search of reassurance, and the gratifications obtained by positive peer feedback. Importantly, the online presentation(s) modeled by peer feedback and enhanced through digital modification, might differ from reality as individuals seek to present their ideal or real selves, thus creating an online version of themselves that is impossible to live up to in the offline world, as predicted by impression management theory. Social comparison with this unattainable version of the self might lead to increased dissatisfaction with the real self, and the anxiety that the real self might disappoint others. This dissatisfaction and anxiety could lead to increased efforts to "improve" the real self through excessive dieting and exercise resulting in eating disorder symptoms. This type of engagement with the Internet is likely to be the most frequent and pervasive, and therefore these types of pathways deserve increased research attention.

Third, the Internet and social media may also be used to participate in weight and shape focused peer groups and communities. Here, the content of social interactions is centered on weight and shape concerns, sometimes to extreme extents such as in pro-eating disorder communities. Unlike in the second pathway, in online communities such as these, individuals may never interact offline. The aim is not to move online relationships offline, but rather to use the Internet as a means of bringing together people who share a common interest. Thus, concerns about the correspondence between one's online and offline selves may not be a central issue. In contrast, the online self is felt to correspond strongly to the real self, and aspects of identity that may lead to marginalization or stigmatization in the offline world are reinforced as central aspects of identity. Perceptions of the prevalence or pathological nature of certain behaviors or attitudes may also become skewed through interactions with similar minded individuals. Thus, involvement in weight and shape centered communities may reinforce the centrality of appearance or eating disorders to identity and lead to a perception of false consensus regarding the extreme nature of these beliefs or behaviors that could act as a barrier to recovery or treatment seeking. This type of Internet engagement is the most active, in that others are sought out, and the emotional investment in the online group is greatest. For these reasons, this type of Internet use may be related to the most severe forms of eating disorders, but may also be associated with the greatest protective factors among online communities promoting positive body image and healthy eating attitudes.

\section{Usefulness and Future Directions}

The integrated model brings together aspects of the theoretical frameworks discussed above, and integrates them in a manner that aims to capture the different aspects of Internet and social media use. One of the main contributions of the model is that it accounts for interactions with others through the Internet as well as the central aspect of control of self-presentation. Furthermore, the hypothesized feedback loop considers how certain gratifications obtained from the Internet and social media might prompt an individual to continue to engage with the online world despite negative feedback or outcomes. Thus, the model brings together the strengths of the frameworks described above and aims to overcome the limitations associated with each framework when considered in isolation.

Grounded in this model, future research should aim to increase our understanding of the relationship between Internet and social media use and body image and eating concerns. First, greater attention needs to be paid to the role of different types of Internet use. In particular, it is critical to examine how "engagement" with the internet, such as through contributions and postings, might reveal a different relationship with body image and eating concerns as opposed to "exposure." It is important to understand to what extent, and how, the interactive aspects of the Internet as well as the creation and curating of an online persona are related to body image and eating concerns. Specifically, the proposed model hypothesizes that peer feedback would emerge as a moderator of this relationship, but also that it would influence future online participation. These relationships need to be tested. In addition, the integrated model suggests that perceived discrepancy between the online and the actual self, resulting from social comparison, would increase feelings of body dissatisfaction and eating pathology. This relationship should also be empirically investigated. Relatedly, research should aim to clarify whether the relationship between Internet use and body image and eating concerns is dose-dependent or whether adolescents need to engage with the Internet to a certain extent for these relationships to appear. These lines of research should aim to clarify whether certain ways of using the Internet confer greater risk for increased body image and eating concerns.

Second, the mediators of the effects of Internet and social media use on body image and eating concerns should be identified. The proposed model suggests that media-ideal internalization, body surveillance and self-objectification, and social comparison mediate the effects of Internet and 
social media use on body image and eating concerns. Research testing these mediated pathways would contribute to our understanding of the mechanisms through which the Internet impacts body image and eating concerns.

Third, it is important to identify the variables that might act as moderators of the relationships represented in the model. Such variables might include demographic characteristics such as age and gender, as well as psychological dimensions such as trait body image related variables, self-esteem, and motivations for Internet use including social support, need for belonging, or appearance feedback/information. Clarifying these moderators will help to identify individuals who might be most vulnerable to the effect of Internet and social media use on body image and eating concerns.

Fourth, there is a need to explore how participation in online communities with a focus on weight and shape might influence the centrality of weight, shape, and eating behavior to identity, and may therefore maintain eating pathology. Increasing our understanding of the ways in which these communities provide support for individuals will augment our capacity to help individuals find appropriate offline resources that may be less deleterious, or use the online resources in ways that are less harmful. Research on these communities should aim to clarify the processes through which individuals create, become integrated into, but also leave such communities. The distal results of this work will contribute to increasing early identification and treatment-seeking among adolescents suffering from clinical eating disorders.

Finally, and importantly, the integrated model does not propose a fixed valence for the relationships it includes (positive or negative). It is presented as a model of risk; however, it is equally crucial to explore each of the above topics with a view to identifying ways in which the Internet might contribute to decreasing body image and eating concerns. Specifically, it is important to identify which modes of Internet use might promote positive body image through decreasing media-ideal internalization, self-objectification, and body dissatisfaction and shame. Similarly, identifying modifiable individual characteristics that might moderate the relationship between Internet use and body image and eating concerns could provide avenues for intervention efforts. In addition, identifying ways in which online communities support positive body image and healthy eating attitudes would help inform educational interventions among adolescents and parents.

\section{Conclusion}

This review presented a number of theoretical frameworks that have been used to conceptualize and understand body image concerns and eating pathology. In addition, it also presented an integrated theory that builds upon the most useful aspects of each of these theories in order to provide a framework within which to clarify the relationships between body image concerns and eating pathology among adolescents. The Internet and social media may likely become one of the most important sociocultural influences on body image concerns and eating pathology within the next decades, and increasing our understanding of the ways in which engaging with the online world can be helpful or detrimental is critical. In addition, adolescents constitute one of the most important developmental groups among which to examine these effects given their heightened risk for developing body image and eating concerns (Levine and Murnen 2009) as well as their likelihood to use the Internet as a context for engaging in the processes identified here as putative mechanisms of the deleterious effects of Internet use on body image and eating behaviors (Peter et al. 2005; Valkenburg and Peter 2007, 2011). The present framework aims to contribute to moving forward in this research direction and developing empirically supported models that may then guide and inform prevention and treatment.

Acknowledgments Many thanks to Professor Susan Paxton for her thoughtful comments on an earlier version of the manuscript.

\section{Compliance with Ethical Standards}

Conflict of interest The authors report no conflict of interests.

\section{References}

Anton, S. D., Perri, M. G., \& Riley, J. R, I. I. I. (2000). Discrepancy between actual and ideal body images: Impact on eating and exercise behaviors. Eating Behaviors, 1, 153-160.

Aubrey, J. S., \& Frisby, C. M. (2011). Sexual objectification in music videos: A content analysis comparing gender and genre. Mass Communication and Society, 14, 475-501. doi:10.1080/ 15205436.2010.513468.

Bargh, J. A., McKenna, K. Y., \& Fitzsimons, G. M. (2002). Can you see the real me? Activation and expression of the "true self" on the Internet. Journal of Social Issues, 58, 33-48.

Borzekowski, D., \& Bayer, A. M. (2005). Body image and media use among adolescents. Adolescent Medicine Clinics, 16(2), 289-313. doi:10.1016/j.admecli.2005.02.010.

Borzekowski, D. L. G., \& Rickert, V. I. (2001). Adolescent cybersurfing for health information: A new resource that crosses barriers. Archives of Pediatric Adolescent Medicine, 155, 813-817. doi:10.1001/archpedi.155.7.813.

Borzekowski, D. L., Schenk, S., Wilson, J. L., \& Peebles, R. (2010). e-Ana and e-Mia: a content analysis of pro-eating disorder Web sites. American Journal of Public Health, 100, 1526-1534. doi:10.2105/AJPH.2009.172700.

Bosch, T. (2011). Young women and 'technologies of the self': Social networking and sexualities. Agenda, 25, 75-86. doi:10.1080/ 10130950.2011 .630579 .

Brenner, J., \& Smith, A. (2013). $72 \%$ of online adults are social networking users. Washington, DC: Pew Internet and American Life Project. 
Brown, L. S. (1989). Fat-oppressive attitudes and the feminist therapist: Directions for change. Women \& Therapy, 8(3), 19-30.

Brown, J. D., \& Bobkowski, P. S. (2011). Older and newer media: patterns of use and effects on adolescents' health and well-being. Journal of Research on Adolescence, 21(1), 95-113. doi:10. 1111/j.1532-7795.2010.00717.x.

Buchholz, A., Henderson, K. A., Hounsell, A., Wagner, A., Norris, M., \& Spettigue, W. (2007). Self-silencing in a clinical sample of female adolescents with eating disorders. Journal of the Canadian Academy of Child and Adolescent Psychiatry, 16, 158-163.

Cash, T. F., Melnyk, S. E., \& Hrabosky, J. I. (2004). The assessment of body image investment: An extensive revision of the Appearance Schemas Inventory. International Journal of Eating Disorders, 35, 305-316. doi:10.1002/eat.10264.

Cialdini, R. B., \& de Nicholas, M. E. (1989). Self-presentation by association. Journal of Personality and Social Psychology, 57, 626-631.

Clay, D., Vignoles, V. L., \& Dittmar, H. (2005). Body image and selfesteem among adolescent girls: Testing the influence of sociocultural factors. Journal of Research on Adolescence, 15(4), 451-477. doi:10.1111/j.1532-7795.2005.00107.x.

Custers, K., \& Van den Bulck, J. (2009). Viewership of pro-anorexia websites in seventh, ninth and eleventh graders. European Eating Disorders Review, 17(3), 214-219.

Daniel, S., \& Bridges, S. K. (2010). The drive for muscularity in men: Media influences and objectification theory. Body Image, 7, 32-38. doi:10.1016/j.bodyim.2009.08.003.

de Vries, D., Peter, J., de Graaf, H., \& Nikken, P. (2015). Adolescents' social network site use, peer appearance-related feedback, and body dissatisfaction: Testing a mediation model. Journal of Youth and Adolescence. doi:10.1007/s10964-0150266-4.

Donnelly, A. M. (2011). Read my profile: Internet profile culture, young women, and the communication of power. In M. Ames \& S. H. Burcon (Eds.), Women and language: Essays on gendered communication across media (pp. 167-183). North Carolina: McFarland.

Doornwaard, S. M., Bickham, D. S., Rich, M., ter Bogt, T. F., \& van den Eijnden, R. J. (2015). Adolescents' use of sexually explicit Internet material and their sexual attitudes and behavior: Parallel development and directional effects. Developmental Psychology, 51(10), 1476-1488

Eichhorn, K. C. (2008). Soliciting and providing social support over the Internet: An investigation of online eating disorder support groups. Journal of Computer-Mediated Communication, 14, 67-78. doi:10.1111/j.1083-6101.2008.01431.x.

Ellison, N. B., Hancock, J. T., \& Toma, C. L. (2012). Profile as promise: A framework for conceptualizing veracity in online dating self-presentations. New Media \& Society, 14, 45-62. doi: $10.1177 / 1461444811410395$.

Fahs, B., \& Gohr, M. (2012). Superpatriarchy meets cyberfeminism: Facebook, online gaming, and the new social genocide. MP An Online Feminist Journal, 3(6), 1-40.

Fernandes, C. A., Rodgers, R. F., \& Franko, D. L. (2013). "Yo/Eu Gorda? Nunca!" (Me, fat? Never!): An exploration of Latino and English appearance-related micro-aggressions on Twitter. Paper presented at the International Conference on Eating Disorders, Montreal, QC.

Fitzsimmons-Craft, E. E. (2011). Social psychological theories of disordered eating in college women: Review and integration. Clinical Psychology Review, 31, 1224-1237. doi:10.1016/j.cpr. 2011.07.011.

Forney, K. J., Holland, L. A., \& Keel, P. K. (2012). Influence of peer context on the relationship between body dissatisfaction and eating pathology in women and men. International Journal of Eating Disorders, 45(8), 982-989. doi:10.1002/eat.22039.
Forston, M. T., \& Stanton, A. L. (1992). Self-discrepancy theory as a framework for understanding bulimic symptomatology and associated distress. Journal of Social and Clinical Psychology, 11, 103-118.

Fredrickson, B. L., \& Roberts, T.-A. (1997). Objectification theory: Toward understanding women's lived experiences and mental health risks. Psychology of Women Quarterly, 21, 173-206. doi:10.1111/j.1471-6402.1997.tb00108.x.

Freedhoff, Y., \& Sharma, A. M. (2009). "Lose 40 pounds in 4 weeks": Regulating commercial weight-loss programs. Canadian Medical Association Journal, 180, 367.

Frisén, A., Berne, S., \& Lunde, C. (2014). Cybervictimization and body esteem: Experiences of Swedish children and adolescents. European Journal of Developmental Psychology, 11, 331-343. doi:10.1080/17405629.2013.825604.

Gibbs, J. L., Ellison, N. B., \& Heino, R. D. (2006). Self-presentation in online personals the role of anticipated future interaction, selfdisclosure, and perceived success in Internet dating. Communication Research, 33(2), 152-177.

Gilbert, S., \& Thompson, J. K. (1996). Feminist explanations of the development of eating disorders: Common themes, research findings, and methodological issues. Clinical Psychology: Science and Practice, 3, 183-202.

Hall, P. C., West, J. H., \& McIntyre, E. (2012). Female selfsexualization in MySpace. com personal profile photographs. Sexuality and Culture, 16, 1-16. doi:10.1007/s12119-011-90950 .

Hesse-Biber, S., Leavy, P., Quinn, C. E., \& Zoino, J. (2006). The mass marketing of disordered eating and eating disorders: The social psychology of women, thinness and culture. Women's Studies International Forum, 29(2), 208-224. doi:10.1016/j.wsif. 2006.03.007.

Higgins, E. T. (1987). Self-discrepancy: A theory relating self and affect. Psychological Review, 94, 319-340.

Hudson, J. I., Hiripi, E., Pope, H. G., \& Kessler, R. C. (2007). The prevalence and correlates of eating disorders in the National Comorbidity Survey Replication. Biological Psychiatry, 61, $348-358$.

Hunter, N. (2011). Beauty is in the eye of the retoucher: Why photoshopped magazine images require regulation. Women's Rights Law Reporter, 33, 82-150.

Hussin, M., Frazier, S., \& Thompson, J. K. (2011). Fat stigmatization on YouTube: A content analysis. Body Image, 8, 90-92. doi:10. 1016/j.bodyim.2010.10.003.

Hutchinson, D. M., \& Rapee, R. M. (2007). Do friends share similar body image and eating problems? The role of social networks and peer influences in early adolescence. Behaviour Research and Therapy, 45(7), 1557-1577. doi:10.1016/j.brat.2006.11.007.

Ison, J., \& Kent, S. (2010). Social identity in eating disorders. European Eating Disorders Review, 18, 475-485.

Keery, H., Van den Berg, P., \& Thompson, J. K. (2004). An evaluation of the tripartite influence model of body dissatisfaction and eating disturbance with adolescent girls. Body Image, 1, 237-251. doi:10.1002/erv.1001.

Knauss, C., Paxton, S., \& Alsaker, F. (2008). Body dissatisfaction in adolescent boys and girls: Objectified body consciousness, internalization of the media body ideal and perceived pressure from media. Sex Roles, 59, 633-643. doi:10.1007/s11199-0089474-7.

Krayer, A., Ingledew, D. K., \& Iphofen, R. (2008). Social comparison and body image in adolescence: A grounded theory approach. Health Education Research, 23, 892-903. doi:10.1093/her/ cym076.

Lampard, A. M., MacLehose, R. F., Eisenberg, M. E., NeumarkSztainer, D., \& Davison, K. K. (2014). Weight-related teasing in the school environment: associations with psychosocial health 
and weight control practices among adolescent boys and girls. Journal of Youth and Adolescence, 43(10), 1770-1780. doi:10. 1007/s10964-013-0086-3.

LaRose, R., \& Eastin, M. S. (2004). A social cognitive theory of Internet uses and gratifications: Toward a new model of media attendance. Journal of Broadcasting \& Electronic Media, 48, 358-377. doi:10.1207/s15506878jobem4803_2.

Lavender, J. M., Wonderlich, S. A., Crosby, R. D., Engel, S. G., Mitchell, J. E., Crow, S. J., et al. (2013). Personality-based subtypes of anorexia nervosa: Examining validity and utility using baseline clinical variables and ecological momentary assessment. Behaviour Research and Therapy, 51, 512-517. doi:10.1521/pedi.2007.21.3.340.

Levine, M. P., \& Murnen, S. K. (2009). "Everybody knows that mass media are/are not [pick one] a cause of eating disorders": A critical review of evidence for a causal link between media, negative body image, and disordered eating in females. Journal of Social and Clinical Psychology, 28, 9-42. doi:10.1521/jscp. 2009.28.1.9.

Lin, L., \& Reid, K. (2009). The relationship between media exposure and antifat attitudes: The role of dysfunctional appearance beliefs. Body Image, 6, 52-55.

Lindberg, S. M., Grabe, S., \& Hyde, J. S. (2007). Gender, pubertal development, and peer sexual harassment predict objectified body consciousness in early adolescence. Journal of Research on Adolescence, 17(4), 723-742. doi:10.1111/j.1532-7795.2007.00544.x.

Madden, M., Lenhart, A., Duggan, M., Cortesi, S., \& Gasser, E. (2013). Teens and technology 2013. Washington, DC: Pew Internet and American Life Project.

Mazur, E., \& Kozarian, L. (2010). Self-presentation and interaction in blogs of adolescents and young emerging adults. Journal of Adolescent Research, 25(1), 124-144. doi:10.1177/0743558 409350498.

McKenna, K. Y., Green, A. S., \& Gleason, M. E. (2002). Relationship formation on the Internet: What's the big attraction? Journal of Social Issues, 58, 9-31. doi:10.1111/1540-4560.00246.

McKinley, N. M., \& Hyde, J. S. (1996). The objectified body consciousness scale. Psychology of Women Quarterly, 20, 181-215.

Murnen, S. K., \& Smolak, L. (2009). Are feminist women protected from body image problems? A meta-analytic review of relevant research. Sex Roles, 60, 186-197. doi:10.1007/s11199-0089523-2.

Mussap, A. J. (2007). The relationship between feminine gender role stress and disordered eating symptomatology in women. Stress and Health, 23, 343-348. doi:10.1002/smi.1152.

Nathanson, A. I., \& Botta, R. A. (2003). Shaping the effects of television on adolescents' body image disturbance the role of parental mediation. Communication Research, 30(3), 304-331. doi:10.1177/0093650203030003003.

National Campaign to Prevent Teen and Unplanned Pregnancy (NCPTUP). (2008). Sex and tech: Results from a survey of teens and young adults. Retrieved from http://www.thenationalcam paign.org/sextech/PDF/SexTech_Summary.pdf, 12 December 2013.

Neumark-Sztainer, D., Falkner, N., Story, M., Perry, C., Hannan, P. J., \& Mulert, S. (2002). Weight-teasing among adolescents: Correlations with weight status and disordered eating behaviors. International Journal of Obesity, 26(1), 123-131. doi:10.1038/sj. ijo.0801853.

Nichter, M., \& Nichter, M. (2001). Fat talk: What girls and their parents say about dieting. Cambridge: Harvard University Press.

Norwood, S. J., Bowker, A., Buchholz, A., Henderson, K. A., Goldfield, G., \& Flament, M. F. (2011). Self-silencing and anger regulation as predictors of disordered eating among adolescent females. Eating Behaviors, 12(2), 112-118. doi:10.1016/j. eatbeh.2011.01.009.
Paxton, S. J., Schutz, H. K., Wertheim, E. H., \& Muir, S. L. (1999). Friendship clique and peer influences on body image concerns, dietary restraint, extreme weight-loss behaviors, and binge eating in adolescent girls. Journal of Abnormal Psychology, 108(2), 255-266. doi:10.1037/0021-843x.108.2.255.

Pea, R., Nass, C., Meheula, L., Rance, M., Kumar, A., Bamford, H., \& Yang, S. (2012). Media use, face-to-face communication, media multitasking, and social well-being among 8-to 12-year-old girls. Developmental Psychology, 48(2), 327. doi:10.1037/a0027030.

Pempek, T. A., Yermolayeva, Y. A., \& Calvert, S. L. (2009). College students' social networking experiences on Facebook. Journal of Applied Developmental Psychology, 30, 227-238. doi:10.1016/j. appdev.2008.12.010.

Peter, J., \& Valkenburg, P. (2007). Adolescents' exposure to a sexualized media environment and their notions of women as sex objects. Sex Roles, 56, 381-395. doi:10.1007/s11199-006-9176-y.

Peter, J., Valkenburg, P. M., \& Schouten, A. P. (2005). Developing a model of adolescent friendship formation on the Internet. CyberPsychology \& Behavior, 8(5), 423-430. doi:10.1089/cpb. 2005.8.423.

Posavac, H. D., Posavac, S. S., \& Posavac, E. J. (1998). Exposure to media images of female attractiveness and concern with body weight among young women. Sex Roles, 38, 187-201. doi:10. 1023/A:1018729015490.

Raacke, J., \& Bonds-Raacke, J. (2008). MySpace and Facebook: Applying the uses and gratifications theory to exploring friendnetworking sites. CyberPsychology \& Behavior, 11, 169-174. doi:10.1089/cpb.2007.0056.

Reich, S. M. (2010). Adolescents' sense of community on Myspace and Facebook: A mixed-methods approach. Journal of Community Psychology, 38, 688-705. doi:10.1002/jcop.20389.

Rich, E. (2006). Anorexic dis(connection): managing anorexia as an illness and an identity. Sociology of Health \& Illness, 28, 284-305. doi:10.1111/j.1467-9566.2006.00493.x.

Rodgers, R., \& Chabrol, H. (2009). The impact of exposure to images of ideally thin models on body dissatisfaction in young French and Italian women. L'Encéphale, 35, 262-268. doi:10.1016/j. encep.2008.05.003.

Rodgers, R. F., McLean, S. A., \& Paxton, S. J. (2015). Longitudinal relationships among internalization of the media ideal, peer social comparison, and body dissatisfaction: Implications for the tripartite influence model. Developmental Psychology, 51(5), 706-713.

Rodgers, R. F., Melioli, T., Laconi, S., Bui, E., \& Chabrol, H. (2013). Internet addiction symptoms, disordered eating and body image avoidance. Cyberpsychology, Behavior, and Social Networking, 16, 56-60. doi:10.1089/cyber.2012.1570.

Rodgers, R. F., Paxton, S. J., \& Chabrol, H. (2009). Effects of parental comments on body dissatisfaction and eating disturbance in young adults: A sociocultural model. Body Image, 6(3), 171-177. doi:10.1016/j.bodyim.2009.04.004.

Rodgers, R. F., Paxton, S. J., \& McLean, S. A. (2014). A biopsychosocial model of body image concerns and disordered eating in early adolescent girls. Journal of Youth and Adolescence, 43(5), 814-823. doi:10.1007/s10964-013-0013-7.

Rodgers, R. F., Skowron, S., \& Chabrol, H. (2012). Disordered eating and group membership among members of a pro-anorexic online community. European Eating Disorders Review, 20, 9-12. doi:10.1002/erv.1096.

Rogers, C. R. (1951). Client-centered therapy: Its current practice, implications and theory. London: Constable.

Rohlinger, D. A. (2002). Eroticizing men: Cultural influences on advertising and male objectification. Sex Roles, 46, 61-74. doi:10.1023/A:1016575909173.

Sabik, N. J., \& Tylka, T. L. (2006). Do feminist identity styles moderate the relation between perceived sexist events and 
disordered eating? Psychology of Women Quarterly, 30(1), 77-84. doi:10.1111/j.1471-6402.2006.00264.x.

Salafia, E. H. B., \& Gondoli, D. M. (2011). A 4-year longitudinal investigation of the processes by which parents and peers influence the development of early adolescent girls' bulimic symptoms. The Journal of Early Adolescence, 31(3), 390-414.

Schlegel, R. J., \& Hicks, J. A. (2011). The true self and psychological health: Emerging evidence and future directions. Social and Personality Psychology Compass, 5, 989-1003. doi:10.1111/j. 1751-9004.2011.00401.x.

Schlenker, B. R. (1980). Impression management: The self-concept, social identity, and interpersonal relations: Brooks/Cole Publishing Company Monterey, CA.

Schutz, H. K., Paxton, S. J., \& Wertheim, E. H. (2002). Investigation of body comparison among adolescent girls. Journal of Applied Social Psychology, 32, 1906-1937. doi:10.1111/j.1559-1816. 2002.tb00264.x.

Sessions, L. F. (2009). You looked better on MySpace: Deception and authenticity on the Web 2.0. First Monday. doi:10.5210/fm. v14i7.2539. http://uncommonculture.org/ojs/index.php/fm/arti cle/view/2539. Accessed 11 November 2014

Sharpe, H., Musiat, P., Knapton, O., \& Schmidt, U. (2011). Pro-eating disorder websites: facts, fictions and fixes. Journal of Public Mental Health, 10, 34-44. doi:10.1108/17465721111134538.

Sharpe, H., Naumann, U., Treasure, J., \& Schmidt, U. (2013). Is fat talking a causal risk factor for body dissatisfaction? A systematic review and met-analysis. International Journal of Eating Disorders, 46(7), 643-652. doi:10.1002/eat.22151.

Siibak, A. (2009). Constructing the self through the photo selectionvisual impression management on social networking websites. Cyberpsychology: Journal of Psychosocial Research on Cyberspace, 3, 1. http://cyberpsychology.eu/view.php?cisloclanku= 2009061501\&article $=1$. Accessed 11 November 2014 .

Slater, A., \& Tiggemann, M. (2002). A test of objectification theory in adolescent girls. Sex Roles, 46(9-10), 343-349.

Slater, A., Tiggemann, M., Hawkins, K., \& Werchon, D. (2012). Just one click: A content analysis of advertisements on teen Web sites. Journal of Adolescent Health, 50, 339-345. doi:10.1016/j. jadohealth.2011.08.003

Snyder, R. (1998). Self-discrepancy theory, standards for body evaluation, and eating disorder symptomatology among college women. Women and Health, 26, 69-84. doi:10.1300/J013v 26n02_05.

Stafford, T. F., Stafford, M. R., \& Schkade, L. L. (2004). Determining uses and gratifications for the Internet. Decision Sciences, 35, 259-288. doi:10.1111/j.00117315.2004.02524.x.

Stankiewicz, J., \& Rosselli, F. (2008). Women as sex objects and victims in print advertisements. Sex Roles, 58, 579-589. doi:10. 1007/s11199-007-9359-1.

Stewart, M.-C., Schiavo, R. S., Herzog, D. B., \& Franko, D. L. (2008). Stereotypes, prejudice and discrimination of women with anorexia nervosa. European Eating Disorders Review, 16, 311-318. doi:10.1002/erv.849.

Strano, M. M. (2008). User descriptions and interpretations of selfpresentation through Facebook profile images. Cyberpsychology: Journal of Psychosocial Research on Cyberspace, 2, 1. http:// cyberpsychology.eu/view.php?cisloclanku=2008110402\&article $=1$. Accessed 11 November 2014.

Striegel-Moore, R. H., Silberstein, L. R., \& Rodin, J. (1993). The social self in bulimia nervosa: public self-consciousness, social anxiety, and perceived fraudulence. Journal of Abnormal Psychology, 102(2), 297-303.

Suler, J. (2004). The online disinhibition effect. Cyberpsychology \& Behavior, 7, 321-326. doi:10.1089/1094931041291295.

Szymanski, M. L., \& Cash, T. F. (1995). Body-image disturbances and self-discrepancy theory: Expansion of the Body-Image
Ideals Questionnaire. Journal of Social and Clinical Psychology, 14, 134-146. doi:10.1521/jscp.1995.14.2.134.

Tajfel, H. (1982). Social psychology of intergroup relations. Annual Review of Psychology, 33, 1-39.

Tao, Z. L., \& Liu, Y. (2009). Is there a relationship between Internet dependence and eating disorders? A comparison study of Internet dependents and non-Internet dependents. Eating and Weight Disorders, 14, e77-e83.

Thompson, J. K., Heinberg, L. J., Altabe, M., \& Tantleff-Dunn, S. (1999). Exacting beauty: Theory, assessment, and treatment of body image disturbance. Washington, DC, US: American Psychological Association.

Tiggemann, M. (2003). Media exposure, body dissatisfaction and disordered eating: Television and magazines are not the same! European Eating Disorders Review, 11, 418-430. doi:10.1002/ erv.502.

Tiggemann, M., \& Miller, J. (2010). The Internet and adolescent girls' weight satisfaction and drive for thinness. Sex Roles, 63, 79-90. doi:10.1007/s11199-010-9789-z.

Tiggemann, M., \& Slater, A. (2013). NetGirls: The Internet, Facebook, and body image concern in adolescent girls. International Journal of Eating Disorders, 46, 630-633. doi:10.1177/ 0272431613501083.

Toma, C. L., \& Hancock, J. T. (2010). Looks and lies: The role of physical attractiveness in online dating self-presentation and deception. Communication Research, 37, 335-351. doi:10.1177/ 0093650209356437.

U.S. Federal Trade Commission. (2000). Privacy online: Fair information practices in the electronic marketplace. A report to congress. Washington, DC

Valkenburg, P. M., \& Peter, J. (2007). Preadolescents' and adolescents' online communication and their closeness to friends. Developmental Psychology, 43(2), 267. doi:10.1037/0012-1649. 43.2.267.

Valkenburg, P. M., \& Peter, J. (2011). Online communication among adolescents: An integrated model of its attraction, opportunities, and risks. Journal of Adolescent Health, 48(2), 121-127. doi:10. 1016/j.jadohealth.2010.08.020.

van den Berg, P., Thompson, J. K., Obremski-Brandon, K., \& Coovert, M. (2002). The tripartite influence model of body image and eating disturbance: A covariance structure modeling investigation testing the mediational role of appearance comparison. Journal of Psychosomatic Research, 53, 1007-1020. doi:10.1016/S0022-3999(02)00499-3.

Vitousek, K. B., \& Hollon, S. D. (1990). The investigation of schematic content and processing in eating disorders. Cognitive Therapy and Research, 14, 191-214. doi:10.1007/bf01176209.

Von Soest, T., \& Wichstrøm, L. (2009). Gender differences in the development of dieting from adolescence to early adulthood: A longitudinal study. Journal of Research on Adolescence, 19(3), 509-529. doi:10.1111/j.1532-7795.2009.00605.x.

Walsh, C. S. (2008). Girls challenging patriarchy through multimodal design and participation in online communities of practice. [Report]. Literacy Learning: The Middle Years, 16(2), 16+.

Webb, H. J., \& Zimmer-Gembeck, M. J. (2014). The role of friends and peers in adolescent body dissatisfaction: A review and critique of 15 years of research. Journal of Research on Adolescence, 24(4), 564-590. doi:10.1111/jora.12084.

Wertheim, E. H., Paxton, S. J., Schutz, H. K., \& Muir, S. L. (1997). Why do adolescent girls watch their weight? An interview study examining sociocultural pressures to be thin. Journal of Psychosomatic Research, 42, 345-355. doi:10.1016/S00223999(96)00368-6.

Winzelberg, A. (1997). The analysis of an electronic support group for individuals with eating disorders. Computers in Human Behavior, 13, 393-407. doi:10.1016/S0747-5632(97)00016-2. 
Young, G., \& Whitty, M. (2011). Progressive embodiment within cyberspace: Considering the psychological impact of the supermorphic persona. Philosophical Psychology, 24, 537-560.

Yu, J., \& Cude, B. (2009). 'Hello, Mrs. Sarah Jones! We recommend this product!' Consumers' perceptions about personalized advertising: Comparisons across advertisements delivered via three different types of media. International Journal of Consumer Studies, 33, 503-514. doi:10.1080/09515089.2011.556606.

Zaitsoff, S. L., Geller, J., \& Srikameswaran, S. (2002). Silencing the self and suppressed anger: Relationship to eating disorder symptoms in adolescent females. European Eating Disorders Review, 10, 51-60. doi:10.1002/erv.418. 